\title{
SABOR DE VENENO: A VANGUARDA PAULISTA NA CENA ARTÍSTICO-MUSICAL BRASILEIRA DOS ANOS 1980
}

Gilberto Xavier da Silva*

RESUMO:

\begin{abstract}
Este estudo objetiva avaliar em que sentido e por quais procedimentos Arrigo Barnabé, Itamar Assumpção, Rumo, Premeditando o Breque (Premê) e Língua de Trapo, integrantes do que se denominou Vanguarda Paulista, evidenciaram uma postura estética renovadora no cenário artístico-musical brasileiro, no início dos anos 1980. As produções da Vanguarda Paulista configuraram-se como uma rede complexa de linguagens, tornando relevantes as relações entre os sentidos, meios $e$ códigos, pelo entrecruzamento dos diferentes sistemas de signos que as compuseram.
\end{abstract}

PALAVRAS-CHAVE: Vanguarda Paulista, vanguardas musicais, música brasileira nos anos 1980.

Nos anos 1980, surgiu, em São Paulo, uma geração de músicos que ficou conhecida como Vanguarda Paulista. Os compositores Arrigo Barnabé e Itamar Assumpção e os grupos Rumo, Premeditando o Breque (Premê) e Língua de Trapo, integrantes dessa vanguarda - que emergiu como uma movimentação artístico-musical alternativa e independente -, produziram trabalhos bem diversificados.

Vários foram os procedimentos utilizados pela Vanguarda Paulista em suas produções, dentre os quais se destacam o canto falado, as interseções efetivadas com a vanguarda musical do início do século XX (Shoenberg, Webern e Berg) e com a estética dos quadrinhos; a apropriação crítica de expedientes alinhados ao kitsch, ao brega, assim como o caráter intersemiótico que subjaz à confecção de capas e encartes de discos dessa vanguarda.

* Doutor em Letras: Literatura e outros Sistemas Semióticos (Área de concentração: Literatura Comparada), 2004. 


\section{EMTESE}

Belo Horizonte, v. 9, p. I-28I, dez. 2005

Nessa perspectiva, tomo os procedimentos intertextuais, neles incluindo principalmente a paródia, para que se entenda como e por que a Vanguarda Paulista se mostrou como uma conformação estética distinta em meio às transformações conceituais, culturais e sociopoliticas por que passava o Brasil, nos anos 1980. O distanciamento crítico respaldado pela ironia que é inerente à paródia permite melhor analisar, interpretar e avaliar as múltiplas vozes discursivas envolvidas em constantes jogos de ambigüidades (Huttcheon, 1985: 37-38) presentes nas produções dos integrantes da Vanguarda Paulista. Confrontando-se estilistica e discursivamente com modelos artístico-musicais do passado, por exemplo, os músicos dessa vanguarda posicionaram-se em tensão diante desses modelos, ativando não só uma relação intertextual, mas principalmente novas formas de produções estéticas.

Acentuadamente dinâmicas, as produções dos integrantes da Vanguarda Paulista processaram-se por meio de variadas correlações entre diferentes e peculiares sistemas de signos, articulando-se, portanto, pela prática das mais diversas formas de apropriações e mesmo pelas construções auto-referenciais. Desse modo, além da paródia, tomo outros desdobramentos intertextuais, como a paráfrase, o pastiche, a citação e mesmo a tradução para proceder ao estudo e à análise das produções dos integrantes da Vanguarda Paulista.

Desse modo, este trabalho orienta-se pelo viés intertextual, entendido não apenas como um processo comparativo de inter-relacionamentos, em que se toma apenas o texto em sua imanência. Cabe considerar que o próprio vocábulo "texto" tem diversos usos e variadas conotações, podendo-se entender "texto" tanto como produção escrita quanto como composição de complexas tramas e urdiduras estéticas, sociais, políticas, econômicas e culturais.

Nas diversas formas de apropriação observadas nas produções dos grupos e compositores da Vanguarda Paulista, ecoam vozes situadas nas inter-relações artísticas que o objeto revela em si e vozes desse objeto em meio ao contexto do qual ele emerge. Nesse sentido, o objeto-disco deve ser entendido como algo que envolve o texto e o seu contexto sem necessariamente sublevar ou eliminar um ou outro, mas tentando processar um diálogo fundamentado, exatamente, na tensão resultante do atrito entre eles. 
Projetando novas dinâmicas artísticas, os integrantes da Vanguarda Paulista não priorizaram apenas a feição melódico-musical de seus discos, que passaram a ser apresentados e compostos como objetos sobre os quais se emolduram todas as relações que envolvem a produção e a recepção: a composição das linhas melódicas e das letras, a forma de divulgação e os espetáculos, assim como a confecção das capas. Estas, mais que cumprir funções de mera embalagem, passaram a participar do conteúdo programático que o LP - o objeto - pretendia conter: nos arredores da produção, passou-se a tramar a sua receptibilidade, pois, "tal como vitrinas de exposição, testemunhos ou amostras, seus transbordamentos" (Compagnon, 1996: 70) passaram a valorizá-1as, promovendo, assim, a sua amplificação significativa, uma vez que a recepção da obra passou a requerer o manejamento não só de certo aparato auditivo mas também espáciovisual. Desse modo, a dimensão plástica das capas (principalmente as do Premê e as do Língua de Trapo) revela-se substancialmente significativa, trazendo à tona uma efetiva carga semântica, na qual as formas visuais e as palavras se ligam por elos de contigüidade ou similaridade, como se pode observar, por exemplo, nas capas de 0 melhor dos iguais, do Premê, e do primeiro disco do Língua de Trapo.

Em 0 melhor dos iguais (disco lançado pelo Premê, em 1985), a exposição, na capa, de uma série de palitos de fósforo, cotonetes, clipes e palitos de dente alinhados, reforça a idéia contida no título do disco. A imagem da capa denota os objetos referidos, mas conota diferentes sentidos pelo deslocamento do contexto, assumindo outros significados possíveis de leitura.

Por um 1ado, estabelecia-se uma crítica à enxurrada extraordinária de LPs, compactos, singles e coletâneas de grupos e cantores que faziam sucesso com músicas que instantaneamente alcançavam boas posições nas paradas, mas desapareciam tão rapidamente como surgiam, assim como aos discos dos considerados medalhões da MPB, que interpretavam, raras exceções, quase que os mesmos compositores (às vezes, as mesmas canções) com os mesmos estilos de $\operatorname{arranjo.}$

Por outro lado, num universo em que as coisas podem ser facilmente reproduzidas e/ou substituídas e estar ao alcance de todos, os objetos 


\section{EM TESE}

Belo Horizonte, v. 9, p. I-28I, dez. 2005

expostos nessa capa equivalem também, ironicamente, ao grupo e às suas canções: são materiais a serem consumidos e descartados.

Da música erudita ao rock e ao funk, da bossa nova ao brega, diversos gêneros musicais eram batidos pelo liqüidificador irônico, satírico e parodístico do Premê, cujo humor, cabe ressaltar, foi sempre, antes de tudo, musical.

A forte ligação com a sátira e a paródia também irá marcar a produção do Língua de Trapo, que, já em seu primeiro disco, com título homônimo e uma capa chapada em azul, trazia apenas o nome da banda escrito a partir de letras extraídas de marcas e logotipos de multinacionais, como o "L" da Light, o "N" da Nestlé, o "T" da Texaco, o "A" da Atlantic, e o dabliu inscrito numa circunferência conformando a letra "0" da logomarca da Volkswagen; e, em meio a essas, 0 "®" de marca registrada e o símbolo que indica a abreviatura paleográfica de Jesus Cristo (X.P.T.0), visualmente semelhante à letra "P". Já num primeiro contato, o grupo paulistano anunciava uma marcante postura ácida, ferina e debochada, mostrando a fluência de sua "língua de trapo".

A imagem exposta nessa capa irá participar significativamente do objetodisco como um todo, tornando-o, nessa medida, uma montagem intersemiótica: sua análise e decodificação deverão levar em conta tanto os signos verbais e os sonoros como os visuais, que, em combinação, se desdobram, verbo-voco-visualmente, na leitura interpretativa do disco como um todo.

Os elementos perigráficos, portanto, anunciam, como numa vitrine, um conteúdo extremamente debochado, que irá conformar as instâncias verbais e melódicas dessa produção. Assim, a primeira faixa do LP, "Burrice precoce", por exemplo, ao ritmo de "iê-iê-iê", apresenta, em forma de paródia, uma releitura das canções da Jovem Guarda, particularmente aquelas cantadas por Roberto Carlos; já "0 que é isso, companheiro?", em ritmo de uma toada sertaneja e interpretada à maneira das velhas duplas caipiras como Alvarenga e Ranchinho, tem como alvo os episódios das guerrilhas urbanas durante o regime militar, particularmente aquele em que se envolveu 0 jornalista e escritor Fernando Gabeira, autor do livro do qual foi apropriado o título da canção. 
Em outra perspectiva, o Rumo, ao acomodar o procedimento do "canto falado" da música contemporânea ao leque das entoações brasileiras, desenvolveu um estilo peculiar de compor e interpretar canções. 0 trabalho do grupo consistia em extrair textos melódicos ou melodias textualizadas da fala cotidiana, conformandoos em canções predominantemente narrativas e próximas das crônicas - particularmente as de dimensões lúdicas e/ou líricas. 0 canto falado, procedimento que tem suas raízes no formalismo lingüístico e na vanguarda musical erudita das primeiras décadas do século XX (Shoenberg, Webern, Berg), era utilizado pelo grupo no cancioneiro popular brasileiro, mas sob uma perspectiva melódica substancialmente tonal, diferentemente do sprechgesang (canto falado), idealizado por Shoenberg, que 0 introduziu em composições não tonais.

0 sprechgesang é uma modalidade de expressão vocal que fica numa zona intermediária entre o canto e a fala, em que o executante deve se precaver para não cair numa modalidade de fala "cantada", o que efetiva um distanciamento da proposta do Rumo em relação à utilização do canto falado, de acordo com a perspectiva do compositor austríaco, uma vez que as canções do grupo exploram, musicalmente, a riqueza rítmica e melódica que a língua fornece. Desse modo, o grupo explora o ritmo da fala cotidiana em sua sonoridade e espontaneidade, recuperando-o poeticamente no espaço rítmico entoativo da canção, produzindo, dessa forma, a exata interseção entre língua e música e propiciando uma condição ideal para o efeito de maior substancialidade do trabalho estético.

Já Arrigo Barnabé, além de se utilizar do canto falado em incursões dodecafônicas e seriais, revelando uma maior afinidade/proximidade com o sprechgesang, de Shoenberg, principalmente em seus dois primeiros trabalhos, Clara Crocodilo e Tubarões voadores, incorpora, em suas composições, expedientes estéticos provenientes das histórias em quadrinhos. "Tubarões voadores", por exemplo, é uma composição feita para se "ver". Em ajustada sincronicidade, cada fala das personagens se encaixa com o tempo certo para a leitura e a visualização de cada quadrinho (do balão ao conjunto do desenho) que acompanha o disco num encarte especial.

Itamar Assumpção, por sua vez, realizava, em suas composições, uma tradução de variados estilos e gêneros musicais, mas não se restringia a repeti-los simplesmente: ele os "recriava" em novos timbres e, principalmente, ritmos, ao 


\section{EMTESE}

Belo Horizonte, v. 9, p. I-28I, dez. 2005

reambientá-10s, misturando-os a outros ritmos e timbres de procedência africana como os batuques e o jongo. A tradução, em Itamar Assumpção, deve ser entendida como a entende Eneida de Souza, na esteira de Haroldo de Campos, "como atividade criativa, em que a liberdade do tradutor instaura o intercâmbio amoroso entre os textos, embora não se processe a fidelidade ao texto original e sim a sua transgressão" (Souza, 1993: 36), sendo essa atitude transgressora inventiva e criadora. Sobre a importância da dimensão rítmica e percussiva de suas canções, o próprio Itamar Assumpção afirmava que procurava nas palavras um sentido de percussão, que apenas frisasse ou tivesse um efeito específico dentro da canção.

Apesar dessa heterogeneidade, os integrantes da Vanguarda Paulista comungaram de uma inquietação estética, uma vontade consciente de realizar um trabalho musical diferente do que estava sendo posto em circulação e absorvido pelo mercado na época, tornando-se, nesse sentido, vanguardistas, por engendrarem posturas artístico-musicais diferenciadas das que vinham sendo veiculadas pela mídia.

De maneira similar aos tropicalistas, Arrigo Barnabé, Itamar Assumpção, Rumo, Premeditando o Breque (Premê) e Língua de Trapo realizaram uma releitura crítica da cultura brasileira: por meio de procedimentos intertextuais, revitalizaram "dentições" e dicções antropofágicas. Como sentencia Haroldo de Campos (1992: 234-235), a Antropofagia é "o pensamento da devoração crítica do legado cultural universal, elaborado não a partir da perspectiva submissa e reconciliada do 'bom selvagem', mas segundo o ponto desabusado do 'mau selvagem', devorador de brancos, antropófago". A Antropofagia não se condiciona a um ato de submissão, de catequese, mas a uma "transculturação", melhor ainda, a "uma 'transvaloração'", a uma visão crítica da história, da cultura, efetivando tanto apropriações como expropriações, desierarquizando, desconstruindo.

Nessa perspectiva, a matriz digestiva da Antropofagia é reativada pelos integrantes da Vanguarda Paulista, mas em novo contexto cultural, bastante distinto daquele que recebeu o Manifesto de 1928, de 0swald de Andrade, e também já diverso do momento tropicalista. Nos anos 1980, a indústria cultural já se encontrava mais que vacinada e experiente para "absorver a subversão e o veneno da paródia". Como analisa Ismail Xavier (1993: 20), a lógica da indústria cultural "não é outra senão a dessa própria 
operação digestiva projetada numa escala e controlada por quem efetivamente detém o poder".

Desse modo, por um lado, o veneno crítico, irônico e irreverente inoculado pela Vanguarda Paulista testou os limites e a irrelevância da cultura de mercado nos anos 1980, por meio de produções artístico-musicais criativas, inventivas e não raro questionadoras e sarcásticas dos clichês da tradição e do próprio País, revelando, nessa medida, "um retrato em branco e preto da aquarela do Brasil" (Nestrovski, 2002: 39); por outro 1ado, cumpre ressaltar que o apetite do kitsch industrial em seus avanços torna-se voraz devorador desse mesmo veneno, dele se alimentando para regurgitá-10 em formas de uso, de consumo de massa, buscando neutralizar, assim, os seus "efeitos nocivos".

Todavia, se os tropicalistas dessacralizaram "formas culturais mimetizadas, mitificadas e instrumentalizadas" (Favaretto,1995: 42), Arrigo Barnabé, Premê, Itamar Assumpção e Língua de Trapo, apropriando-se do brega, radicalizaram essa dessacralização, devorando mitos, clichês e indefinições que já se constituíam em hipérboles cafonas na sociedade brasileira, e estabeleceram uma crítica corrosiva ao "encortiçamento da cultura e dos centros nervosos do país" (Nestrovski, 2002: 39) ou à estética "made in Paraguai".

Os integrantes da Vanguarda Paulista podem ser vistos como "criadores intempestivos, contra o tempo, em favor de um tempo" (Santiago, 1975: 117). Experimentando diferentes procedimentos de composição, chocaram-se com o sistema estético vigente, reflexo de uma ordem ideológica mais ampla. Esses procedimentos diferenciados utilizados por eles é que, anunciando diferentes posturas estéticas, entraram em confronto com aqueles advindos das manifestações do complexo ideológico dominante, contrariando e mesmo questionando o que ecoava no mercado artístico da época.

Mais do que criticar pela blague, os integrantes da Vanguarda Paulista, ao transferirem, reorganizarem e transcontextualizarem gêneros e estilos, e abordarem de forma criativa e produtiva a tradição, marcaram a "diferença no coração da semelhança", pois souberam ler/ver/ouvir material artístico familiar, recente ou remoto, performando-o com novos olhos e ouvidos, penetrando-o e transformando-o em uma consciência crítica da produção artística dos nossos dias. 


\section{EM TESE}

Belo Horizonte, v. 9, p. I-28I, dez. 2005

Nas rupturas que promoveram, ao fornecer um novo padrão formal de disco e ao questionarem os assentados padrões temáticos da indústria musical de seu tempo, Arrigo Barnabé, Premê, Rumo, Itamar Assumpção e Língua de Trapo protagonizaram criativas e renovadoras produções artístico-musicais nos anos 1980: a exemplar singularidade de suas produções projeta-1hes uma aura cult e vanguardista. Na caixa preta da música brasileira, estão inscritas as sonoridades desses músicos; e onde "essa caixa puder ressoar o que há de mais musical na música, a aceitação daquilo que os sons querem ser, além daquilo que se necessita que sejam, essas sonoridades estarão vivas, pedindo escuta" (Wisnik, 1999: 219) para quem quiser ouvir e provar o saboroso veneno que elas consubstanciaram na cena artístico-musical brasileira dos anos 1980 .

ABSTRACT :

The objective of this study is to evaluate how Vanguarda Paulista, the work of Arrigo Barnabé, Itamar Assumpção, Rumo, Premeditando o Breque (Premê) and Língua de Trapo, established an inventive and innovative aesthetics in the musical scenario during the 1980's. The Vanguarda Paulista configured during its existence a complex variety of intertextual relations and semiotical dialogue.

KEY WORDS: musical vanguards, Brazilian music in the 1980's.

REFERÊNCIAS BIBLIOGRÁFICAS

CALAD0, Carlos. Tropicália: a história de uma revolução musical. São Paulo: Editora 34, 1997.

CAMPOS, Augusto de. Balanço da bossa e outras bossas. 5. ed. São Paulo: Perspectiva, 1993.

CAMPOS, Augusto de. Música de invenção. São Paulo: Perspectiva, 1998.

CAMPOS, Haroldo. O seqüestro do Barroco na formação da literatura brasileira: o caso Gregório de Mattos. Salvador: Fundação Casa de Jorge Amado, 1989.

CAMPOS, Haroldo. Metalinguagem e outras metas. 4. ed. São Paulo: Perspectiva, 1992.

CANCLINI, Néstor García. Consumidores e cidadãos: conflitos multiculturais da civilização. 2. ed. Trad. Maurício Santana Dias e Javier Rapp. Rio de Janeiro: UFRJ, 1996. 
COMPAGNON, Antoine. O trabalho da citação. Trad. Cleonice P. B. Mourão. Belo Horizonte: Editora UFMG, 1996.

DIAS, Marcia Tosta. Os donos da voz: indústria fonográfica brasileira e mundialização da cultura. São Paulo: Editorial Boitempo, 2000.

ENZENSBERGER, Hans Magnus. As aporias da vanguarda. In: Tempo Brasileiro, n. 26-27: 92 [s.d.].

Favaretto, Celso. Tropicália: alegoria, alegria. 2. ed. São Paulo: Ateliê Editorial, 1996.

MANN, William. A música no tempo. Trad. Gradiva Publicações. São Paulo: Martins Fontes, 1987.

MENEZES, Flo. Apoteose de Schoenberg. 2. ed. São Paulo: Ateliê Editorial, 2002.

NESTROVSKI, Arthur (Org.). Música popular brasileira hoje. São Paulo: Publifolha, 2002.

PERRONE-MOISÉS, Leyla. Texto, crítica, escritura. São Paulo: Ática, 1978.

SANTIAGO, Silviano. Vanguarda: um conceito possivelmente e um método. In: ÁVILA, Afonso (0rg). O modernismo. São Paulo: Perspectiva, 1975.

SOUZA, Maria Eneida de. Traço crítico. Belo Horizonte: UFMG / Rio de Janeiro: UFRJ, 1993.

TATIT, Luiz. O cancionista: composições de canções no Brasil. São Paulo: Edusp, 1996.

WISNIK, José Miguel. O som e o sentido: uma outra história das músicas. 2. ed. São Paulo: Companhia das Letras, 1999.

XAVIER, Ismail. Alegorias do subdesenvolvimento. São Paulo: Brasiliense, 1993. 